\title{
Innovation on English Teaching Method PSPT Based on Lexical Chunk Theory and Consecutive Interpretation Process
}

\author{
Yanlin Wang \\ Tourism College, Northwest Normal University, Lanzhou, Gansu Province, China \\ mykyky@163.com
}

Keywords: Teaching Method PSPT, Lexical Chunk theory, Interpretation Process

\begin{abstract}
This paper introduces the original teaching method PSPT by the author. PSPT was created on the the author's consecutive interpretation experiences and the theory of lexical chunks. It is widely acknowledged that lexical chunks worked efficiently in language processing. The input of lexical chunks will help much in the text output both orally and in a written way. On this basis through the deconstruction and reconstruction of sentences PSPT Method succeeds in the input of lexical chunks and the output of text and to much extent eases the difficulty in recitation and retelling of texts in English learning, which will promote the learning efficiency.
\end{abstract}

\section{The theoretical basis}

Lexical chunks were expressed quite differently such as prefabricated routines and patterns, lexicalized sentence stems, lexical phrase, lexical items, multi-word units and so on. Becker firstly put forward the concept of idiosyncratic chunks in 1975. He presented that most of us use a prefabricated build that already has stocks in our brains. Its main function is that when we want to express some ideas, we can extract these components directly without re-formation. In 1993 Lewis put forward the term "lexical chunks" which have been widely used by domestic scholars. As for the lexical chunks Lewis holds that a lexical chunk may be a word or a complete sentence with a fixed pragmatic meaning.

Chomsky's language acquisition hypothesis theory believes that the process of children exercises is "observation-hypothesis-verification-internalization-innovation" $[1]$. The corpus imitated and acquisited by children mostly appears in the form of lexical chunks. Lexical chunks are input and absorbed as the overall structure, and the language is self-generated through the verification and hypothesis of the language system and the internalization into language rules. Therefore, the learning of chunks is an important way of the entire language input and output process.

Lexical chunk theory also has gradually attracted the academic interest of scholars. Search the key words of lexical chunk and teaching, in the past ten years totally 277 articles were found. Besides the academic interest of scholars' rise, another factor could be assumed that lexical chunk theory can benefit the linguistic teaching and learning in practice.

\section{The introduction to PSPT}

\subsection{The definition of PSPT}

PSPT is the abbreviation of the initial letters of points (of information), sentence, paragraph and text. It is defined as an English teaching method which is extracted from the consecutive interpretation (hereafter as CI) process to deconstruct and reconstruct sentences on the theoretical basis of lexical chunks to realize the retelling and recitation of English texts.

\subsection{The creation of PSPT}

The author has been an interpreter and English teacher for over a decade. In the interpretation the author found that the CI notetaking could be used to do a training on retelling and recitation. The process of CI starts from the input of the source language, then the note-taking, further information 
processing and finally it ends with the output of the target language. With the aid of the note-taking memory pressure is greatly reduced, which makes the final language output easier. While in English learning, the retelling or reciting process runs from the input of the source language, then to the information processing, and finally the output of the source language (still). Obviously the process of retelling or reciting within one language is much less difficult than the CI process which happens between the two languages. It could be assumed that if the note-taking method be introduced into the retelling or reciting process, the difficulty of the retelling or reciting would be lowered another time. Therefore, the students will benefit much from the retelling and reciting with less difficulty. Why not to try. Then the author started to analyze its possibility.

The CI flow chart could be described as below:

Obtain the information of source language $\rightarrow$ extract the points of information by notetaking $\rightarrow$ transform into the target language $\rightarrow$ the completion of paragraphs and discourse interpretation

In this process, after receiving the information of the source language, the interpreter should deconstruct the sentence into lexical chunks and take the notes; then with the notes aid, the information points would be connected into a sentence in the target language. Thus the reconstruction of the sentence would be completed. Sentence by sentence, a paragraph then a text would be interpreted into the target language. During the CI processing, the lexical chunks are input, stored and output as independent units which to some extent ease the pressure of the brain in processing the language and smooth the extracting of information.

In CI process it must be noticed that the text is in the transformation from the source language to the target language. While in retelling or recitation of English texts, all things can be done only in one language. Thus the difficulty of transformation process would be greatly reduced. It means that to retell or recite a text, with PSPT a student needs to deconstruct the text in English into lexical chunks, then take the notes(which are also the information points of the sentence) like in CI process, then to connect the information points back into the sentence orally to finish the retelling or recitation.

Derived from the CI process, the PSPT could flow like this:

Obtain the information of a sentence $\rightarrow$ deconstruct the sentence into lexical chunks $\rightarrow$ take the notes of information points $\rightarrow$ connect the information points and reconstruct the sentence under the assistance of the notes $\rightarrow$ sentence by sentence, finish the retelling or recitation of a paragraph $\rightarrow$ paragraph by paragraph, finish the retelling or recitation of a text

Comparing with the CI, PSPT is easier because it does not have the process of transformation from the source language to the target language. Meanwhile in its comparison with common recitation process, PSPT has also become easier due to the input of lexical chunks and the assistance of the notetaking.

\subsection{The application of PSPT in teaching}

PSPT must be systematically applied in teaching. Its application involves the specific teaching purposes, the targeted design of teaching plan, and the organizational class. The teacher can adopt the method to help the students retell or recite the whole text or several paragraphs aiming to improve their oral capability. While as for the writing classes PSPT could be used to recite some classical articles or beautiful essays. The research of Yinglian Ma found that recitation attracted great attention of many scholars and teachers [2]. The research of Liming Deng points out that the reciting language input provides obvious help in the acquisition and consolidation of lexical chunks and writing ability

[3]. Therefore, the teacher can accordingly apply PSPT in different classes for retelling or reciting purpose.

In the stage of the teaching plan design, the teacher should focus on the lexical chunks recognition, explanation, teaching and learning. To develop the lexical chunks awareness of the students is necessary, which will enable them to learn lexical chunks autonomously and actively. In the beginning of the course, the teacher can arrange several preparation classes for the students to know about the the notetaking of CI and the lexical chunks, which will allow the students to do the 
notetaking and input the lexical chunks in applying the PSPT method. The steps of the method applicaiton in teaching are shown in Figure 1

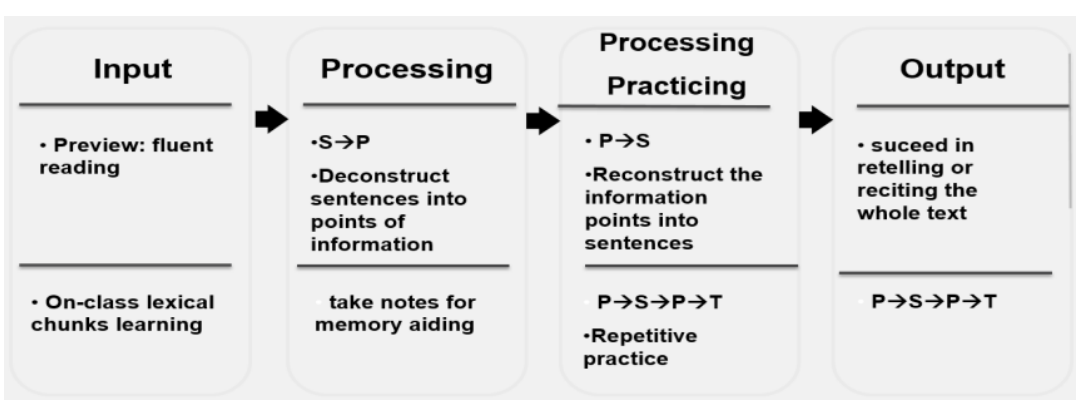

Fig. 1. PSPT application flow.

The points of information which come from the deconstruction of the sentences are the imitation of the CI note-taking. These points are deconstructed into lexical chunks and reconstructed into lexical chunks again in the process, thus the former part from $\mathrm{P}$ (points of information) to $\mathrm{S}$ (sentence) of PSPT is completed. Then sentences will form a paragraph and finally the retelling or recitation of the whole text will be finished. The students are required to practice repeatedly according to the information points paragraph by paragraph till they can retell or recite the text fluently. To popularize the method, the teacher can require the students to recite a designated text with note-taking and demonstrate their achievement on class to reinforce the students' sense of achievement.

\section{The teaching effect verification}

On the class of the Tourism English, the author tested the students on their retelling. With the method of PSPT, a tour guide speech of 1000 words will be recited within 2 class hours. Though students vary in their pronunciation or fluency, it could be accepted that over $80 \%(26 / 30)$ of the students are able to finish the retelling of the tour guide speech. The author conducted two pre-tests and two post-tests, and compared the mean of the pre-test and the post-test. The author found that the scores presented as in Table 1 can clearly show the progress made by the tested students as well as the whole class level.

Table 1. Comparison of the scores of the tested students.

\begin{tabular}{cccc}
\hline Test frequency & Highest score & Lowest score & average \\
\hline Pre-test & 84 & 45 & 73 \\
\hline Post-test & 91 & 62 & 82 \\
\hline
\end{tabular}

PSPT has been conducted for several years and the author conducted three questionnaire surveys in different semesters. The surveys were designed according to Likert Scale. Totally 83 questionnaires were distributed and all were recovered valid.

Table 2. Acceptance and evaluation of PSPT of the tested students

\begin{tabular}{lcc}
\hline \multicolumn{1}{c}{ item } & mean & Standard Deviation \\
\hline $\begin{array}{l}\text { 1.PSPTcan reduce the retelling or reciting } \\
\text { difficulty }\end{array}$ & 3.874 & 0.716 \\
\hline 2.PSPTcan promote my class participation & 4.128 & 0.653 \\
\hline 3.PSPTcan improve the class efficiency & 3.643 & 1.473 \\
\hline 4.PSPT suits me, I will adopt it in self-teaching & 3.852 & 0.957 \\
\hline
\end{tabular}

From the data in Table 2, we can see that the overall evaluation and acceptance of the students for the method are optimistic. The data of item $2(\mathrm{M}=4.128, \mathrm{SD}=0.653)$ shows that the students' perception on the class participation are the most consistent. The data from item 2 presents that they agree that the method can realease them from hard work in retelling or reciting. The standard deviation of item 3 tells that some students are not sure about whether the method can directly improve the class efficiency. The data of item 4 indicate that students tend to accept the method. 


\section{Summary}

This paper introduced the original teaching method PSPT including its definition, application and effect verification. The method is on the lexical chunk basis and created according to the CI notetaking and process. PSPT application is wide as in different English classes to retell or recite texts in an easy and efficient way. The survey conducted by the author proved that PSPT can minimize the difficulty of memorizing text, allowing students to effectively master the learning content and improve the students' participation in the classroom. The success of a text recitation or retelling can stimulate the sense of achievement of the students and arouse their interest in English learning. Aided by the note-taking of information points in retelling or reciting, the students are bound to overcome the psychological obstacles that many of them think to recite a text is a difficult thing.

When using the PSPT teaching method, the lexical chunks learing, sentence deconstruction analysis, method introduction and reinforcement practices are compressed into the classroom, and the student are drilled and achieve their learning objective in the classroom. Through classroom check, students can demonstrate the results of classroom learning, strengthen their sense of achievement, and thus actively promote the classroom learning effect [4] .

\section{References}

[1] Chomsky N, New Horizons in the Study of Language, Cambridge University Press, P165-167, 2000.

[2] Yinglian Ma, Research and review on Linguistic input with recitation, Journal of Hebei United University (social science edition), vol. 14, pp.129-130, 2014.

[3] Liming Deng, Xiangyun Wang, Rearch on validity of the writing ability development of Chinese students in second language based on the reciting language input, J. Foreign Language Education. vol.28. pp.52-56.2007.

[4] Yanlin Wang, the Application of Interpretation Note-taking in Tourism English Teaching and Brief Introduction to PSPT, Journal of the Northwest Adult Education, vol. 4, pp. 49-50. 2012. 